\title{
The Prognostic Values of the Insulin-Like Growth Factor Binding Protein Family in Ovarian Cancer
}

\author{
Ruoyi Zheng $\mathbb{D}^{1}{ }^{1}$ Wenming Chen $\mathbb{D}^{2}{ }^{2}$ Weiting Xia $\mathbb{D}^{1},{ }^{1}$ Jingyu Zheng $\mathbb{D}^{3}$, and Qing Zhou $\mathbb{D}^{1}$ \\ ${ }^{1}$ Department of Gynecology, The First Affiliated Hospital of Wenzhou Medical University, Wenzhou, Zhejiang 325000, China \\ ${ }^{2}$ Department of Obstetrics, The First Affiliated Hospital of Wenzhou Medical University, Wenzhou, Zhejiang 325000, China \\ ${ }^{3}$ Department of Pathology, The First Affiliated Hospital of Wenzhou Medical University, Wenzhou, Zhejiang 325000, China
}

Correspondence should be addressed to Qing Zhou; zhouqing@wzhospital.cn

Received 1 July 2020; Revised 23 September 2020; Accepted 15 October 2020; Published 17 November 2020

Academic Editor: Claude Prigent

Copyright (C) 2020 Ruoyi Zheng et al. This is an open access article distributed under the Creative Commons Attribution License, which permits unrestricted use, distribution, and reproduction in any medium, provided the original work is properly cited.

Purpose. To assess the expression of insulin-like growth factor binding protein (IGFBP) family and its prognostic impact in ovarian cancer (OC) patients. Materials and Methods. The mRNA expression and protein expression of individual IGFBPs in healthy ovarian samples and OC tissues were explored through Oncomine, Gene Expression Profiling Interactive Analysis, and Human Protein Atlas database. Additionally, the prognostic values of the six IGFBP members in patients with OC were evaluated by Kaplan-Meier plotter. Results. IGFBP2 and IGFBP4 mRNA expression were remarkably upregulated in patients with OC. To be specific, the mRNA expression of IGFBP2 was upregulated in patients with serous ovarian cancer (SOC), while IGFBP1/3/4/5/6 mRNA levels were downregulated. In addition, the IGFBP4 protein expression was upregulated in SOC, and the IGFBP6 protein expression was upregulated in both of SOC and endometrioid ovarian cancer (EOC) tissues. High IGFBP1 mRNA levels showed favorable overall survival (OS) and progression-free survival (PFS) in all OC. Meanwhile, increased IGFBP5/6 mRNA levels revealed worsen OS and PFS in all OC patients. IGFBP4/6 mRNA levels predicted unfavorable OS and PFS only in SOC patients. Moreover, the aberrant mRNA expression of IGFBP1/2/4/5/6 was correlated with significantly prognosis in patients receiving different chemotherapeutic regimens. Conclusion. This study indicates that the IGFBP family reveals distinct prognosis in patients with OC. IGFBP1/2/4/5/6 are useful prognostic predictors for chemotherapeutic effect in OC patients, and IGFBP2/4 are potential tumor markers for the diagnosis of OC.

\section{Introduction}

Ovarian cancer $(\mathrm{OC})$ is the most fatal gynecological malignancy worldwide with 286,000 occurrences and 176,000 deaths in 2017 [1]. Owing to the lack of specific symptoms, patients with OC often present with an advanced stage. Epithelial ovarian cancer is considered as the most common type of OC, with various subtypes of serous ovarian cancer (SOC), clear cell ovarian cancer, mucinous ovarian cancer, and endometrioid ovarian cancer (EOC) [2]. Surgery in combination with chemotherapy is the standard treatment recommended by the NCCN guideline for patients with OC of the advanced stage. Nevertheless, 5-year survival is only about $30 \%$ to $40 \%$ in most countries [3]. Therefore, reliable prognostic biomarkers for $\mathrm{OC}$ are needed to improve clinical outcomes.
Insulin-like growth factor binding proteins (IGFBPs), a family of secreted proteins that originally characterized as passive carriers of insulin-like growth factors (IGFs) in the circulation with high-affinity, are composed of 6 identified members (IGFBP1, 2, 3, 4, 5, 6) [4]. Apart from functions within the IGF system, they are acknowledged to play various roles in the extracellular and intracellular circumstances to modulate cell proliferation and apoptosis, as well as survival [5].

The relationships between IGFBPs and cancer prognosis remain contradictory in many studies. IGFBPs may increase cell survival and promote proliferation, while under other conditions, they may suppress tumor growth by stimulating apoptosis and suppressing cell proliferation [4]. Furthermore, there are no consistent or definitive evidences regarding the prognostic impact of IGFBPs in OC. In our study, we assessed the mRNA levels and protein levels of the IGFBP 


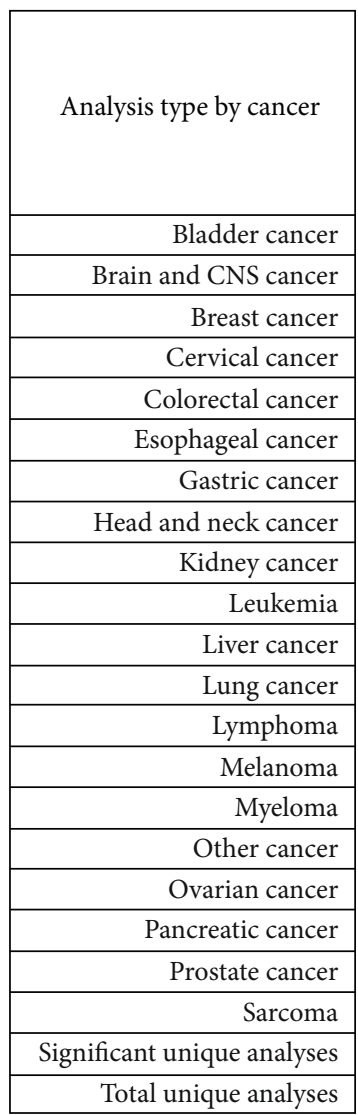

\begin{tabular}{|c|c|c|c|c|c|c|c|c|c|c|c|}
\hline $\begin{array}{c}\text { Cancer } \\
\text { vs. } \\
\text { normal } \\
\text { IGFBP1 }\end{array}$ & $\begin{array}{c}\text { Cancer } \\
\text { vs. } \\
\text { normal } \\
\text { IGFBP2 }\end{array}$ & $\begin{array}{c}\text { Cancer } \\
\text { vs. } \\
\text { normal } \\
\text { IGFBP3 }\end{array}$ & $\begin{array}{c}\text { Cancer } \\
\text { vs. } \\
\text { normal } \\
\text { IGFBP4 }\end{array}$ & $\begin{array}{c}\text { Cancer } \\
\text { vs. } \\
\text { normal } \\
\text { IGFBP5 }\end{array}$ & $\begin{array}{c}\text { Cancer } \\
\text { vs. } \\
\text { normal } \\
\text { IGFBP6 }\end{array}$ \\
\hline & & 1 & 2 & 3 & 1 & & & & 3 & & 4 \\
\hline & & 12 & & 7 & & 4 & & 12 & & 2 & \\
\hline & 9 & & 1 & 2 & 2 & & 1 & 1 & 1 & & 28 \\
\hline & & & & 2 & & & & & 2 & & 1 \\
\hline & & 3 & & 1 & 2 & & & 2 & & & 5 \\
\hline & & & & 8 & & 3 & & 2 & & 1 & \\
\hline & 1 & & 5 & 2 & & 1 & & & 1 & & \\
\hline & & 1 & 2 & 5 & & 1 & & & 5 & 1 & 1 \\
\hline & & & 9 & 8 & & & 4 & & 3 & 2 & 3 \\
\hline & & 4 & 1 & 1 & 2 & 4 & & 1 & 1 & & \\
\hline & 2 & & & 1 & 4 & & 3 & & & 1 & \\
\hline & 2 & 5 & & 17 & & & 2 & 6 & & & 6 \\
\hline 3 & & 4 & & 9 & 1 & 7 & & 8 & & 2 & \\
\hline & & & & 2 & & & & & 2 & & 1 \\
\hline & & & 2 & & 1 & & & & 1 & & \\
\hline & & 2 & 2 & 7 & 1 & 2 & 4 & 2 & 3 & 1 & 3 \\
\hline & 1 & 2 & & & & 1 & 7 & & 7 & & 9 \\
\hline 1 & & & 4 & 6 & & 1 & & 5 & & & \\
\hline & 1 & 2 & & & 2 & & 1 & & 3 & & 3 \\
\hline & & & 4 & 4 & 1 & & 2 & & 1 & & 5 \\
\hline 4 & 16 & 36 & 31 & 84 & 16 & 24 & 23 & 39 & 33 & 10 & 68 \\
\hline 350 & 345 & 352 & 311 & 357 & 354 \\
\hline
\end{tabular}

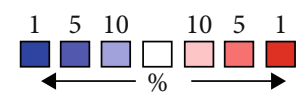

FIgure 1: The mRNA levels of six IGFBPs in various kinds of carcinomas using the Oncomine database. The graph demonstrates the numbers of datasets with remarkably upregulated (red) and downregulated mRNA levels (blue) of the target subtype. The cut-off of $p$ value and fold change was defined as 0.01 and 2 , respectively.

family in OC tissues and normal samples for the first time by using Oncomine datasets, Gene Expression Profiling Interactive Analysis (GEPIA) database, and the Human Protein Atlas (HPA) database. Moreover, we explored the prognosis of the six IGFBP genes in patients with OC through Kaplan-Meier plotter (KM plotter).

\section{Materials and Methods}

2.1. Oncomine Analysis. The Oncomine database [6] (https:// www.oncomine.org), an internet cancer microarray platform containing 715 datasets and 86733 samples, was used to evaluate the IGFBP mRNA expression among various types of carcinoma with cut-off defined as $p$ value $=0.01$, fold change (FC) "2", and gene rank top 10\%. Furthermore, we assessed the mRNA expression of individual IGFBPs between OC and healthy samples by Student's $t$-test. We set up cut-off at $p$ value $=0.01$, fold change " 2 ", and gene rank top $10 \%$ as well.

2.2. GEPIA. GEPIA (http://gepia.cancer-pku.cn) is a network-based tool for processing the RNA expression information, collected from 9,736 carcinomas and 8,587 healthy specimens from GTEx project and TCGA. GEPIA offers diversified functions covering differential expression analysis, profile plotting, survival analysis, and correlation analysis [7]. We explored the IGFBP mRNA expression between SOC and healthy samples, which was evaluated by Student's $t$-test. The IGFBP mRNA expression among different pathological stages of SOC was assessed by the $F$-test. Fold change $>2$ and $p<0.01$ were considered significant.

2.3. HPA. HPA (https://www.proteinatlas.org) is a valuable database providing human transcriptomic and proteomic information presented through Tissue Atlas, Pathology Atlas, and Cell Atlas among 44 various healthy organs, tissues, and 20 kinds of neoplasm [8]. It maps protein levels in normal samples and carcinoma tissues by utilizing immunohistochemistry. In our study, we used HPA to reveal the protein levels of the IGFBP family members in healthy specimens, SOC, and EOC tissues to evaluate whether it is in accordance with the mRNA expression from the GEPIA database.

2.4. KM Plotter. KM plotter [9] (http://kmplot.com/analysis/) was applied to analyze overall survival (OS) and progression- 


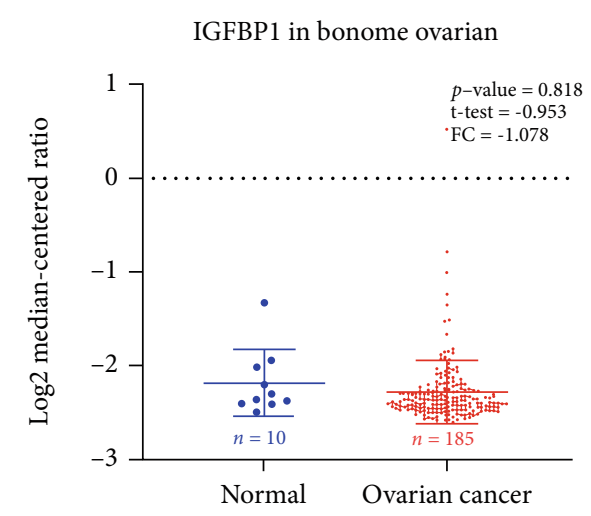

(a)

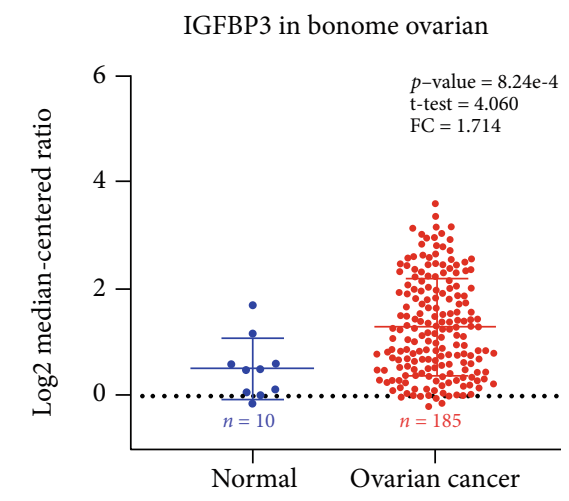

(c)

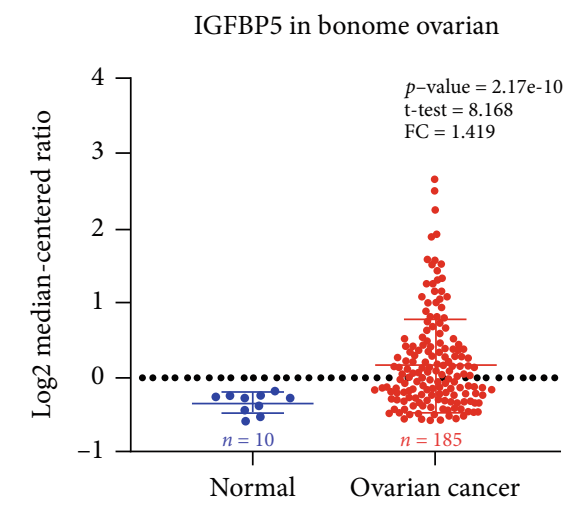

(e)

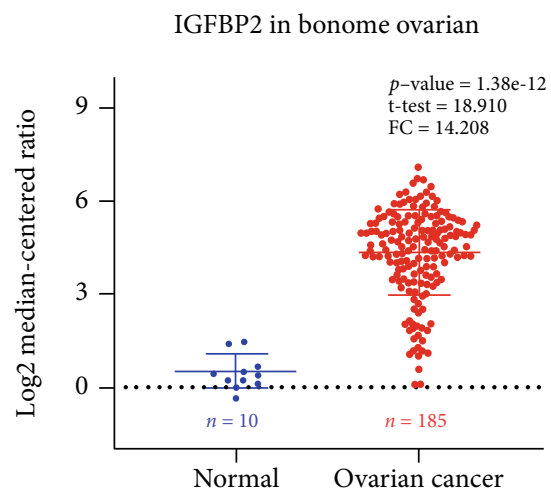

(b)

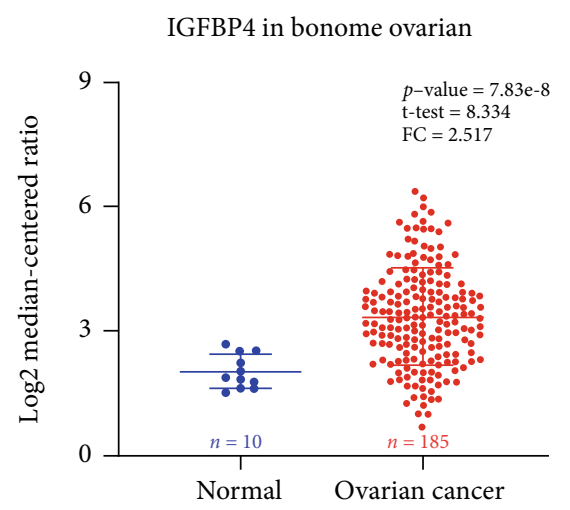

(d)

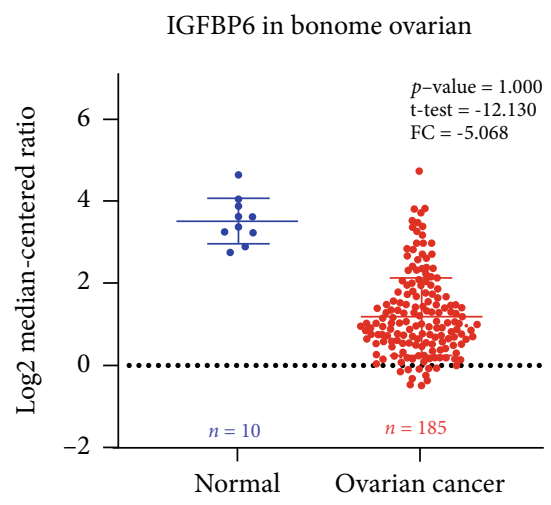

(f)

FIGURE 2: The mRNA levels of six IGFBPs in ovarian cancer and normal ovarian samples using the Oncomine database. (a) IGFBP1. (b) IGFBP2. (c) IGFBP3. (d) IGFBP4. (e) IGFBP5. (f) IGFBP6. The $p$ value was defined as 0.01 , while fold change was set up at 2.

free survival (PFS) of the individual IGFBP mRNA level across 2190 OC patients. Specifically, clinical characteristics consisting of pathological histology, pathological grade, clinical stage, and chemotherapeutic regimen were collected from this database. The patient specimens were separated into "low" and "high" expression groups based on the mRNA expression of IGFBPs with established threshold values. The hazard ratio (HR), 95\% confidence intervals (CIs), and $p$ value were evaluated. Briefly, IGFBP1-6 were calculated in the datasets, respectively, to obtain the Kaplan-Meier survival plots. We defined $p<0.05$ as statistically significant.

\section{Results}

3.1. IGFBP mRNA Expression in OC Patients. With the Oncomine database, we analyzed the mRNA levels of the IGFBP family in various kinds of carcinomas compared with healthy specimens (Figure 1). Subsequently, mRNA levels of individual IGFBPs between OC and normal samples were evaluated as demonstrated in Figure 2. In the study of Bonome Ovarian, we observed that IGFBP2 and IGFBP4 were significantly upregulated in OC compared to healthy specimens [10]. 

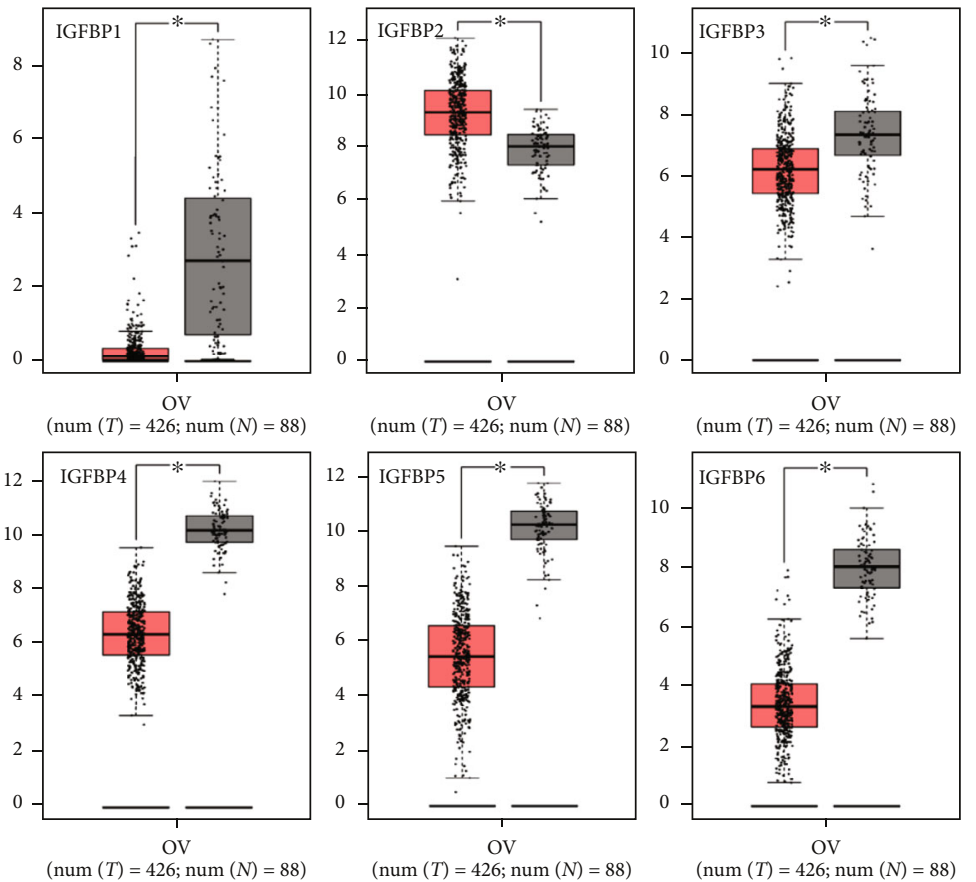

(a)
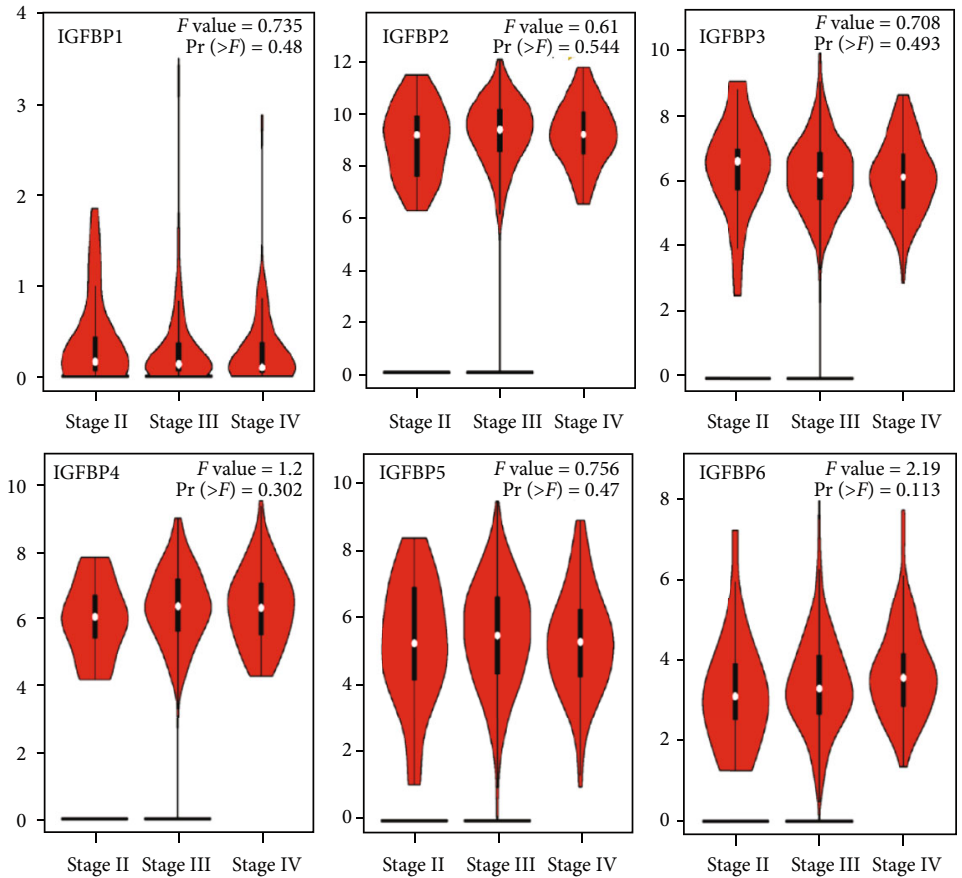

(b)

FIgURE 3: (a) The mRNA expression of six IGFBPs in women with serous ovarian cancer. (b) The levels of IGFBPs in the pathological stage II, III, and IV of serous ovarian cancer (GEPIA database). The cut-off of $p$ value and fold change was set up at 0.01 and 2 , respectively.

With the GEPIA database, we evaluated the mRNA expression of IGFBP genes in SOC samples and normal specimens. IGFBP1, IGFBP3, IGFBP4, IGFBP5, and IGFBP6 mRNA levels were remarkably downregulated in SOC than in healthy ovarian tissues, while IGFBP2 was remarkably higher (Figure 3(a)). No significant difference was found in
mRNA levels of IGFBPs in different tumor pathological stages of SOC (Figure 3(b)).

3.2. IGFBP Protein Expression in OC Patients. With immunohistochemistry staining provided by the HPA, we assessed the IGFBP protein levels between healthy ovarian samples 


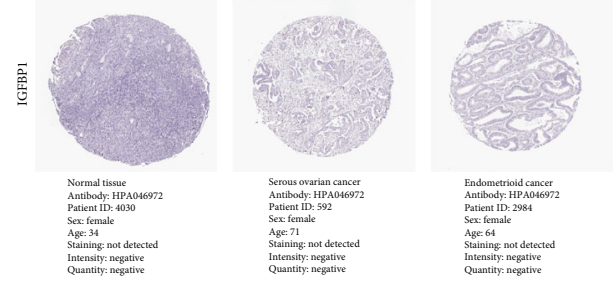

(a)
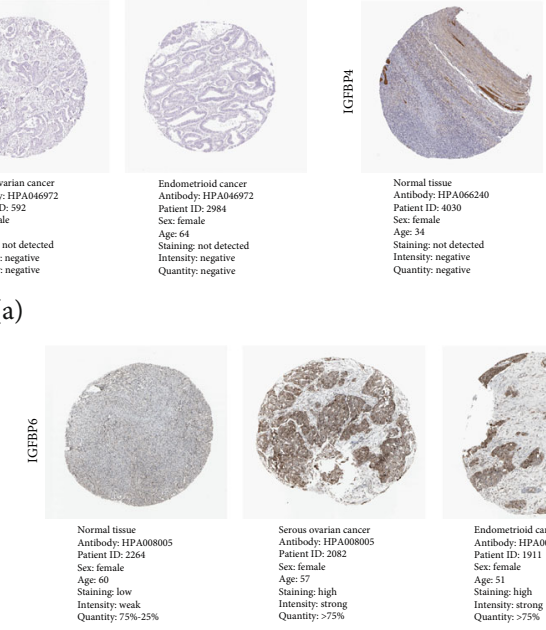

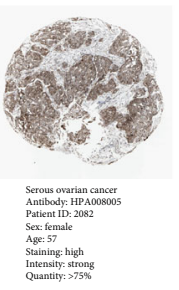

(c)

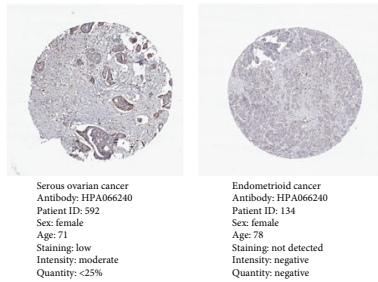

(b)

FIGURE 4: The protein expression of IGFBP1, IGFBP4, and IGFBP6 from the HPA database (The staining images of IGFBP2, IGFBP3, and IGFBP5 were unavailable). (a) IGFBP1. (b) IGFBP4. (c) IGFBP6.

and OC tissues, including SOC and EOC tissues (Figure 4). The immunohistochemical staining images of IGFBP2, IGFBP3, and IGFBP5 are not provided in this study due to its unavailability in the HPA. Both of IGFBP1 and IGFBP4 showed no staining detected in normal ovarian tissues (Figures 4(a) and 4(b)). Using the exact same antibody applied to the 7 examined SOC, there were one case of low staining and six cases of not detected. In addition, all three examined EOC tissues revealed no detection of staining in both of IGFBP1 and IGFBP4. For IGFBP6, stroma cells demonstrated low staining in normal samples (Figure 4(c)). Among six detected SOC tissues, two cases with high staining of IGFBP6, two cases with medium staining, and two cases with low staining were observed. Among the two examined EOC samples, there were one case of high staining and one case of medium staining.

3.3. Prognostic Values of IGFBP $m R N A$ Levels in OC Patients. By using KM plotter, we further examined the prognostic impact of individual IGFBP mRNA levels among OC patients. Initially, we evaluated the prognostic significance of IGFBP1 (Figures 5(a) and 6(a) and Table 1). Elevated IGFBP1 mRNA levels were linked to better OS and PFS in all OC patients and a positive PFS in EOC patients. Furthermore, high expressed IGFBP1 mRNA was related to a better PFS in clinical stage I and II OC patients. Higher IGFBP1 was correlated with better OS and PFS in all OC patients receiving platin chemotherapy regimen.

Next, the prognostic effect of IGFBP2 was assessed (Figures 5(b) and 6(b) and Table 2). The overexpression of IGFBP2 mRNA indicated unfavorable PFS among all OC, EOC, and clinical stage I and II OC patients. Additionally, higher expression of IGFBP2 mRNA predicted a worsen OS in all OC patients received platin chemotherapeutic treatment.

Subsequently, the prognosis of the IGFBP3 was explored (Figures 5(c) and 6(c) and Table 3). Highly expressed IGFBP3 mRNA predicted worse OS in all OC, SOC, patho- logical grade II OC, and clinical stage III and IV OC, and all OC patients received platin chemotherapy regimen. However, IGFBP3 predicted positive PFS in EOC, and all OC patients received taxol and taxol+platin chemotherapeutic regimens.

As demonstrated in Figures 5(d) and 6(d) and Table 4, the overexpression of IGFBP4 was relevant to worsen OS and PFS in SOC and pathological grade II OC patients. High IGFBP4 was linked to worse PFS in pathological grade III OC and clinical stage III and IV OC patients. Furthermore, elevated IGFBP4 mRNA indicated a worsen OS in all OC patients that received platin chemotherapeutic regimen and worse PFS in all OC patients that received taxol and taxol +platin chemotherapy, whereas IGFBP4 revealed better PFS in 51 patients with EOC, 37 patients with pathological grade I OC, and 163 patients with clinical stage I and II OC.

We then assessed the prognostic impact of the IGFBP5 mRNA expression (Figures 5(e) and 6(e),and Table 5). The overexpression of IGFBP 5 mRNA was in relation to worsen OS and PFS in all OC, pathological grade II OC patients, and clinical stage I and II OC patients. IGFBP5 predicted poor OS in SOC and EOC patients as well. However, IGFBP5 demonstrated a positive PFS in women with pathological grade III OC. Additionally, the overexpression of IGFBP5 predicted worse $\mathrm{OS}$ in all $\mathrm{OC}$ women received platin, taxol and taxol+platin chemotherapy, and unfavorable PFS in all patients treated with plain and taxol+platin chemotherapeutic regimens.

The prognosis of IGFBP6 was further detected (Figures 5(f) and 6(f) and Table 6). High expressed IGFBP6 mRNA was linked to worsen OS and PFS in all OC, SOC, and pathological grade III OC patients. IGFBP6 also showed worse PFS in pathological grade II OC and clinical stage III and IV OC patients. Further studies presented that high IGFBP6 was in relation to a poor OS in all OC patients received with platin chemotherapy and poor PFS in all OC women receiving taxol and taxol+platin chemotherapeutic treatments. 

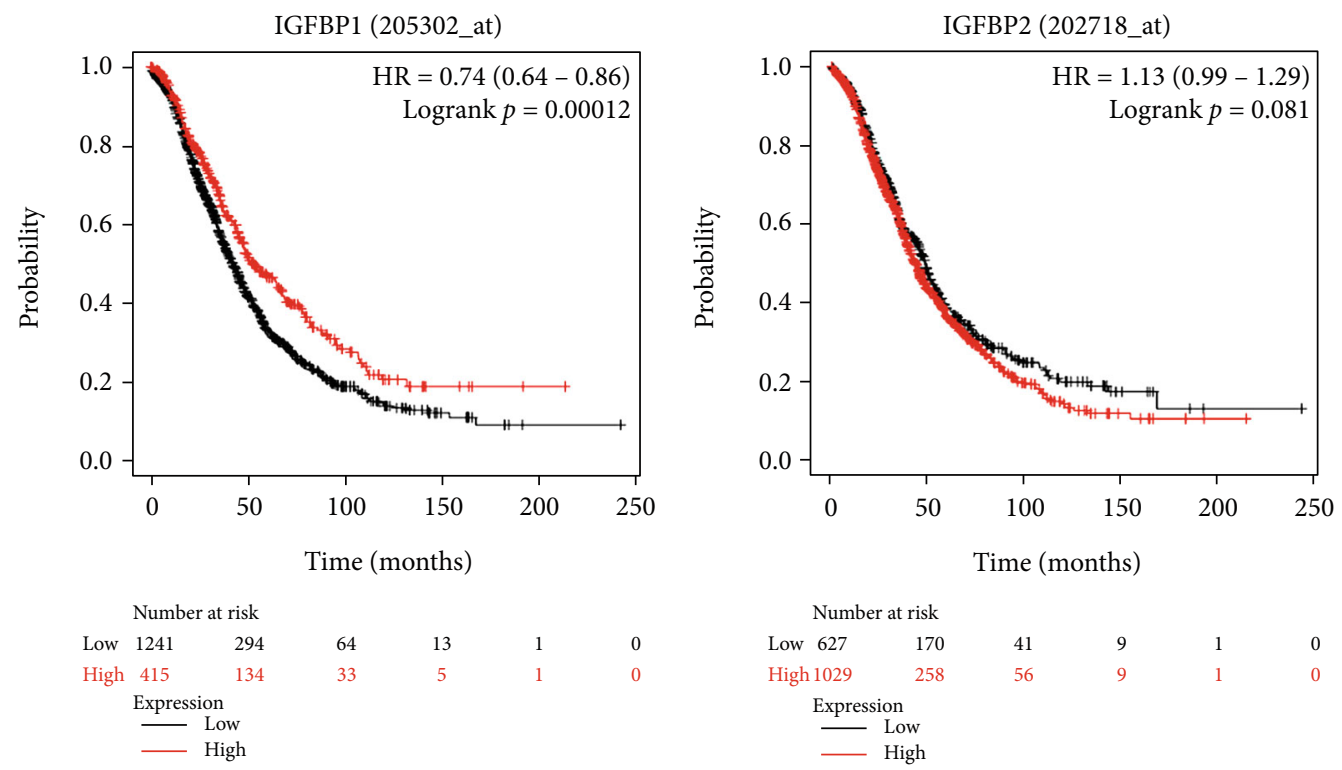

(a)

(b)
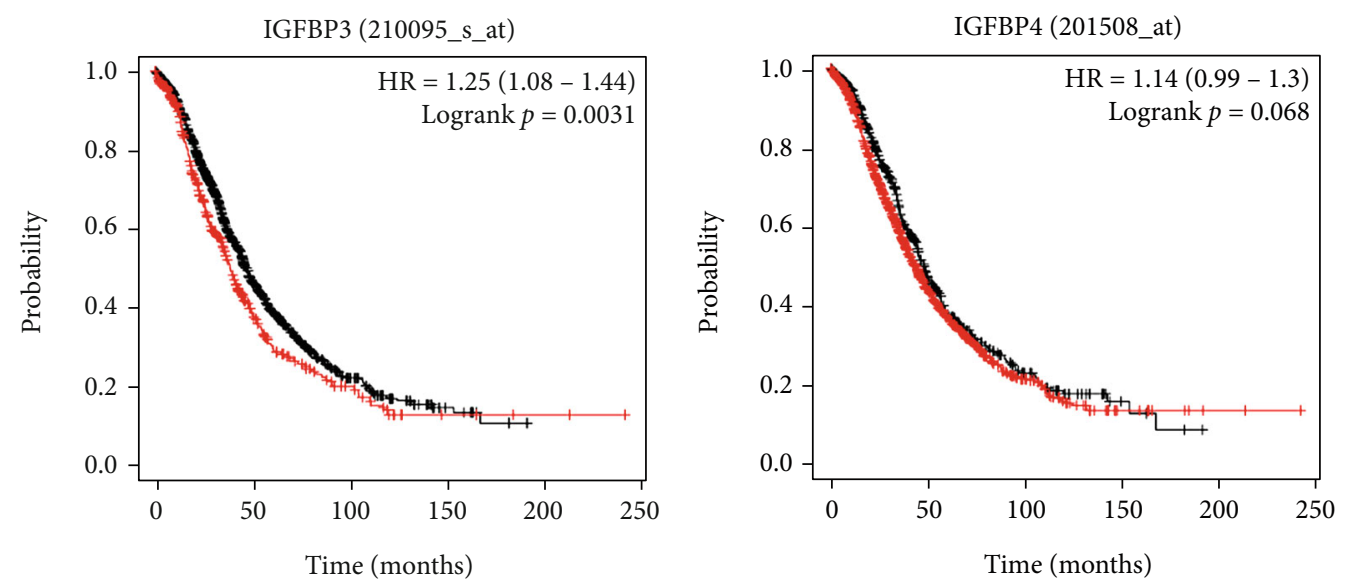

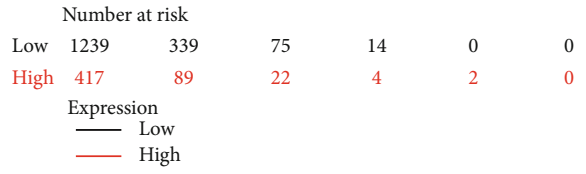

(c)

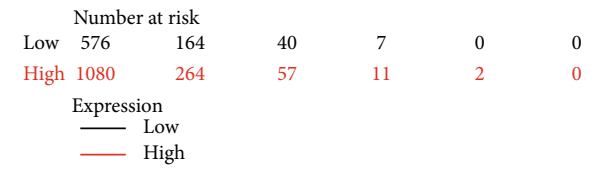

(d)

Figure 5: Continued. 


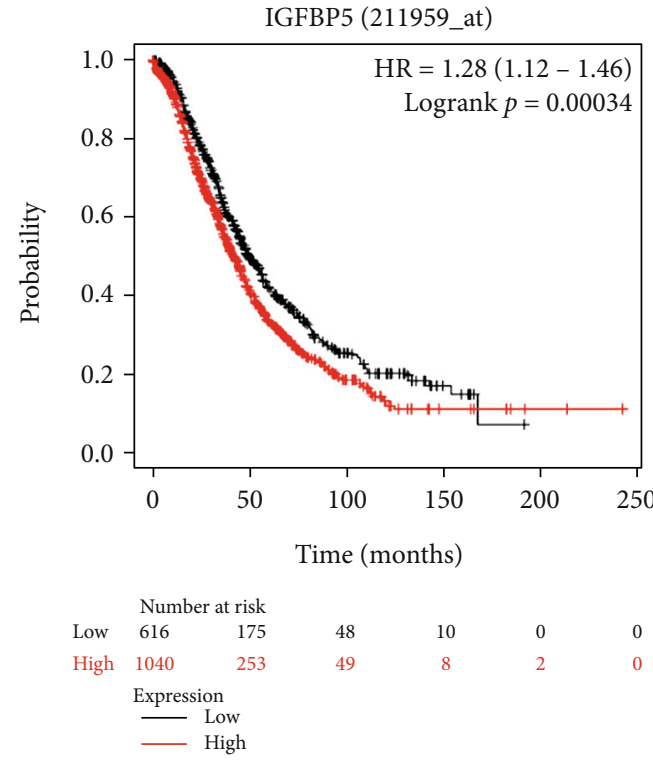

(e)

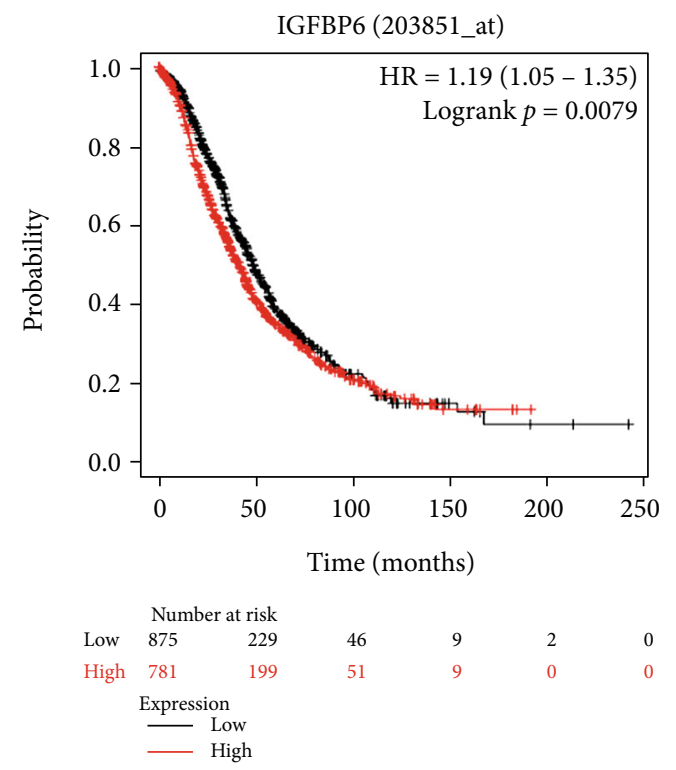

(f)

FIgURE 5: The prognostic impact of six IGFBPs regarding overall survival (OS) of all ovarian cancer using the Kaplan-Meier plotter. (a) The OS curves of IGFBP1 $(n=1656)$. (b) The curves of OS were plotted for IGFBP2 $(n=1656)$. (c) The OS curves of IGFBP3 with $n=1656$. (d) The curves of OS were plotted for IGFBP4 $(n=1656)$. (e) The OS curves of IGFBP5 with $n=1656$. (f) The OS curves of IGFBP6 ( $n=1656$ ). The curves of OS comparing patients with low (black) and high (red) IGFBP mRNA expression were plotted, with a cut-off $p$ value of $<0.05$.

\section{Discussion}

IGFBP family plays a crucial role in modulating essential biological activities in the extracellular and intracellular compartments, such as cell proliferation, angiogenesis, apoptosis, survival, migration, and differentiation $[4,11]$. Under various physiological circumstances, IGFBPs can mediate cellular functions through IGF-dependent or IGFindependent pathways. To our knowledge, we first used bioinformatic methods to evaluate the impact of the IGFBP family comprehensively on OC.

IGFBP1 has increased cell proliferation, cell-matrix adhesion, and regulate survival in schwannoma cells through the integrin $\beta 1 / \mathrm{Src} / \mathrm{FAK}$ pathway [12]. IGFBP1 has also acted as a tumor inhibitor in hepatocellular cancer through downregulation of the MMP expression [13]. Meanwhile, findings on the correlation between the IGFBP1 and prognostic value in different types of carcinoma were inconsistent. Previous researches have revealed that the elevated expression of IGFBP1 is related to shorter time of metastasis and lower survival in gastric carcinoma [14] and prostate cancer [15]. However, several studies have revealed that low levels of IGFBP1 are related to increased risk of tumor progression and significant poor survival in breast cancer [16], colorectal cancer [17], and hepatocellular carcinoma [13]. Studies on the relationship between the predictive values of IGFBP1 and OC are limited. In ovarian clear cell adenocarcinoma, IGFBP1 has specifically expressed in both protein level and mRNA level by using immunohistochemistry and in situ hybridization [18]. A case-control study demonstrated that higher levels of IGFBP1 in plasma were correlated with higher risk of OC [19]. Our results with GEPIA datasets demonstrated that IGFBP1 mRNA levels were significantly downregulated in SOC. Furthermore, KM plotter revealed for the first time that highly expressed IGFBP1 mRNA indicated favorable OS and PFS in all OC and better PFS in women with EOC and clinical stage I and II OC. IGFBP1 also predicted favorable OS and PFS in all OC patients received with platin chemotherapy regimen. Evidence has been accumulated together that elevated levels of IGFBP1 may serve as a significant favorable prognostic predictor in all $\mathrm{OC}$ patients, particularly among patients with early stage and patients who received platin chemotherapy.

IGFBP2 ranks the second most abundant IGFBP in the circulation [20]. Some publications have suggested that IGFBP2 plays a tumor promotor role in glioblastoma through activation of $\beta$-catenin or EGFR-STAT3 pathways $[21,22]$, pancreatic ductal adenocarcinoma via activation of the NF- $\kappa$ B pathway [23], and prostate cancer cells by the androgen-mediated pathway and MAPK-PI3K pathway [24]. Kang et al. have believed that the attenuated expression of IGFBP2 is in relation to worsen OS in rhabdomyosarcoma [25]. However, various studies have clarified that the overexpression of IGFBP2 are related to poorer prognosis in breast cancer [26], endometrial cancer [27], colorectal cancer [28], pancreatic ductal adenocarcinoma [23], lung cancer [29], and glioblastoma [21]. Despite of these controversial results, researches on OC seemed to be consistent. It has been previously reported that increased serum levels of IGFBP2 are linked with tumor grades and stages, predicting a higher recurrent risk and a shortened OS in OC [30]. Similarly, augmented IGFBP2 serum levels are correlated with poorer clinicopathological features and worse prognosis in epithelial ovarian cancer [31]. Besides, Huang et al. have also reported that IGFBP2 levels are higher in patients with worse responses to chemotherapy, which means IGFBP2 might 

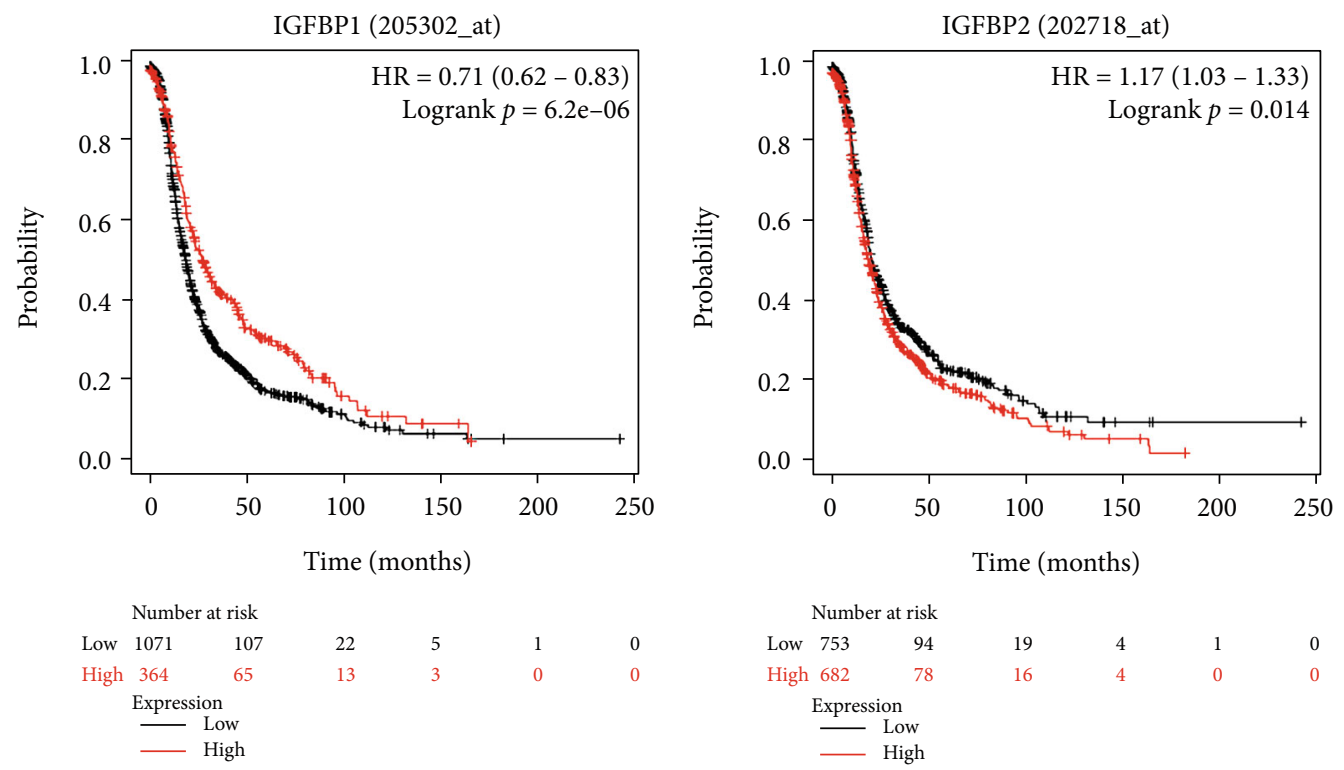

(a)

(b)
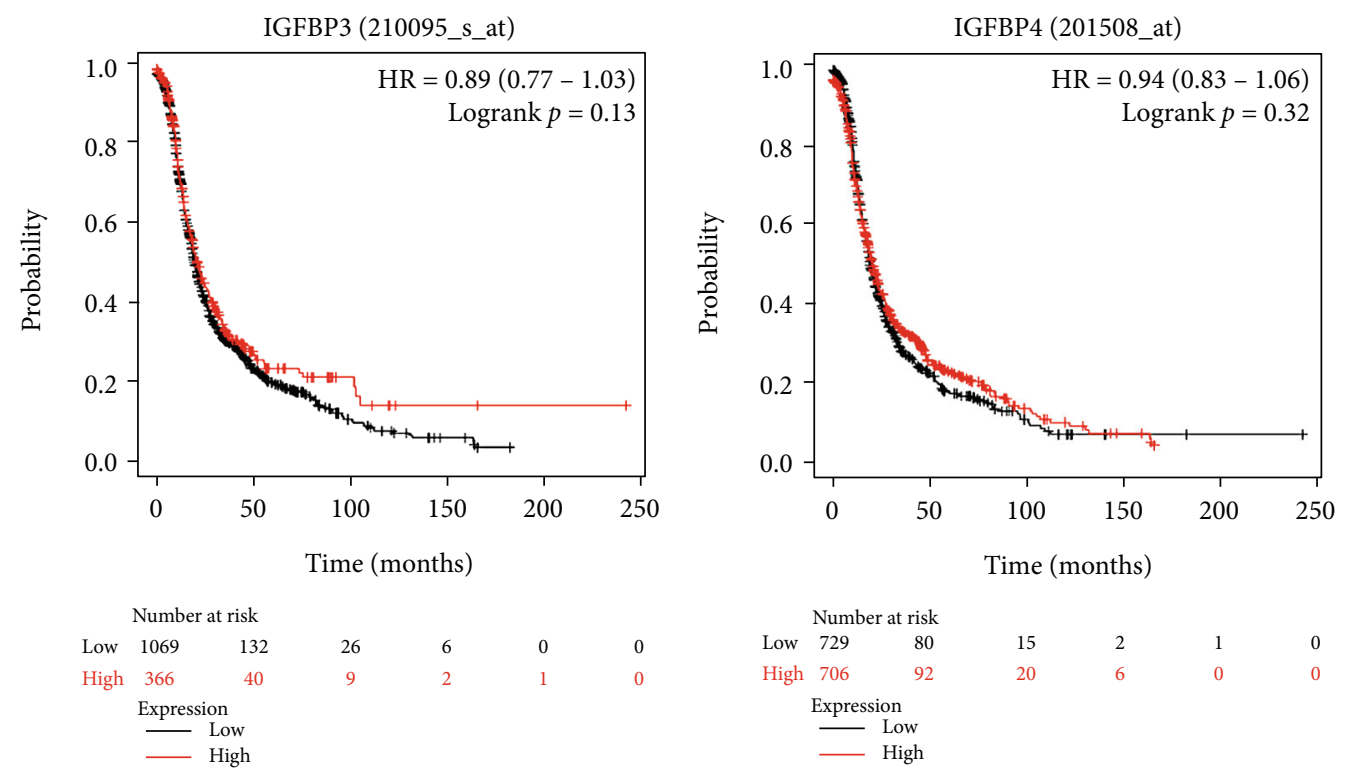

(c)

(d)

Figure 6: Continued. 


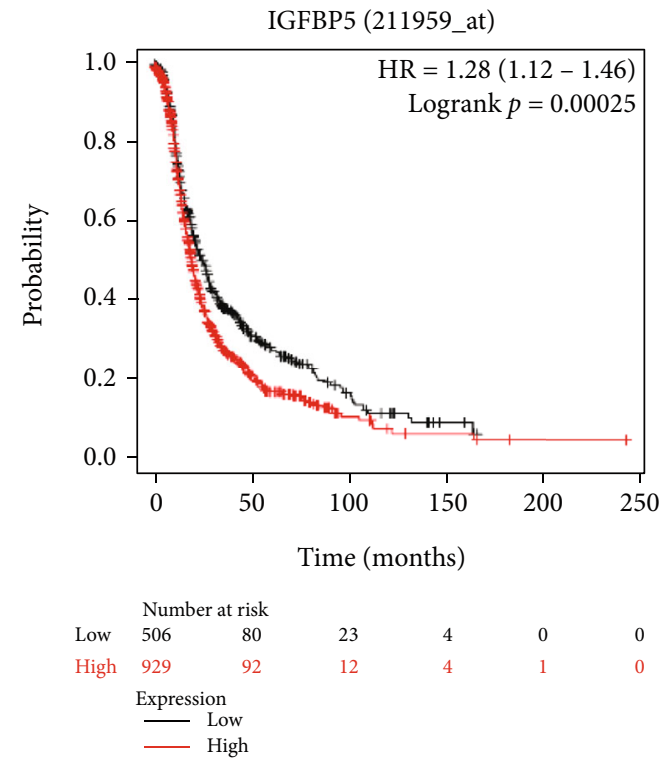

(e)

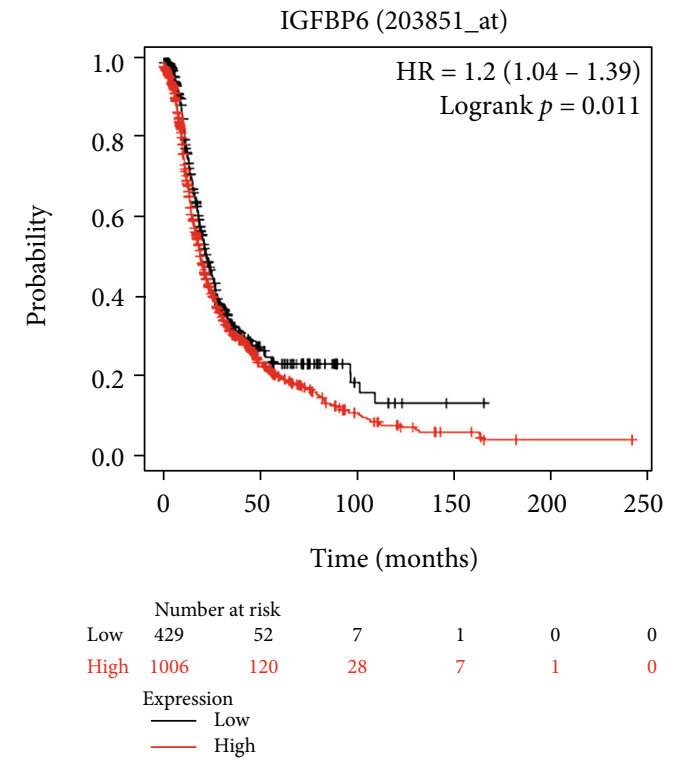

(f)

FIGURE 6: The prognostic value of the IGFBP family in progression-free survival (PFS) of all ovarian cancer using the Kaplan-Meier plotter. (a) The curves of PFS were plotted for IGFBP1 $(n=1435)$. (b) The PFS curves of IGFBP2 with $n=1435$. (c) The curves of PFS were plotted for IGFBP3 with $n=1435$. (d) Plotted PFS curves for IGFBP4 $(n=1435)$. (e) The curves of PFS were plotted for IGFBP5 ( $n=1435)$. (f) Plotted PFS curves for IGFBP6 with $n=1435$. The PFS curves comparing women with low (black) and high (red) IGFBP mRNA expression were plotted, with a cut-off $p$ value of $<0.05$.

TABLE 1: The prognostic value of the IGFBP1 mRNA expression in ovarian cancer.

\begin{tabular}{|c|c|c|c|c|c|c|}
\hline & \multicolumn{3}{|c|}{ Overall survival } & \multicolumn{3}{|c|}{ Progression-free survival } \\
\hline & Cases & HR (95\% CI) & $p$ value & Cases & HR (95\% CI) & $p$ value \\
\hline \multicolumn{7}{|l|}{ Histology } \\
\hline All cancer patients & 1656 & $0.74(0.64-0.86)$ & $0.00012^{*}$ & 1435 & $0.71(0.62-0.83)$ & $6.2 \mathrm{e}-06^{*}$ \\
\hline Serous cancer patients & 1207 & $0.86(0.72-1.03)$ & 0.099 & 1104 & $0.91(0.77-1.07)$ & 0.24 \\
\hline Endometrioid cancer patients & 37 & $2.66(0.3-23.76)$ & 0.36 & 51 & $0.21(0.05-0.91)$ & $0.021^{*}$ \\
\hline \multicolumn{7}{|l|}{ Pathological grades } \\
\hline I & 56 & $0.44(0.17-1.16)$ & 0.09 & 37 & $0.33(0.09-1.23)$ & 0.084 \\
\hline II & 324 & $0.76(0.56-1.03)$ & 0.08 & 256 & $0.87(0.62-1.22)$ & 0.42 \\
\hline III & 1015 & $0.89(0.74-1.08)$ & 0.24 & 837 & $0.88(0.73-1.07)$ & 0.19 \\
\hline \multicolumn{7}{|l|}{ Clinical stages } \\
\hline I and II & 135 & $0.42(0.17-1.04)$ & 0.052 & 163 & $0.41(0.19-0.87)$ & $0.016^{*}$ \\
\hline III and IV & 1220 & $0.86(0.74-1.01)$ & 0.063 & 1081 & $1.11(0.96-1.29)$ & 0.15 \\
\hline \multicolumn{7}{|l|}{ Chemotherapy } \\
\hline Contains platin & 1409 & $0.79(0.67-0.93)$ & $0.005^{*}$ & 1259 & $0.79(0.69-0.91)$ & $0.00094^{*}$ \\
\hline Contains taxol & 793 & $0.85(0.68-1.05)$ & 0.13 & 715 & $1.16(0.96-1.41)$ & 0.13 \\
\hline Contains taxol+platin & 776 & $0.82(0.65-1.02)$ & 0.077 & 698 & $1.16(0.95-1.41)$ & 0.15 \\
\hline
\end{tabular}

${ }^{*} p<0.05$.

act as a predictor of chemotherapy responses, especially in older patients or patients with SOC. In the present study, Oncomine and GEPIA analyses indicated that IGFBP2 mRNA levels were remarkably upregulated in both of OC and SOC in comparison with healthy tissues. Besides, our data from KM plotter datasets found that highly expressed IGFBP2 levels were link to a worse PFS in all OC patients and EOC patients. Furthermore, IGFBP2 also predicted a worsen OS in all OC patients received with platin treatment. Taken together, IGFBP2 may predict unfavorable clinical outcomes in women with OC.

IGFBP3, the most abundant circulating IGFBP, transports around $75 \%$ IGFs in heterotrimeric complexes including acid-labile subunit [5]. IGFBP3 exhibits antitumor effect in prostate carcinoma through crosstalk with the NF$\kappa \mathrm{B}$ pathway and activation of caspase-dependent apoptosis 
TABLE 2: The prognostic value of the IGFBP2 mRNA expression in ovarian cancer.

\begin{tabular}{lccccc}
\hline & Cases & $\begin{array}{c}\text { Overall survival } \\
\text { HR }(95 \% \text { CI })\end{array}$ & $p$ value & Cases & $\begin{array}{c}\text { Progression-free survival } \\
\text { HR }(95 \% \text { CI })\end{array}$ \\
\hline Histology value
\end{tabular}

${ }^{*} p<0.05$.

TABLE 3: The prognostic value of the IGFBP3 mRNA expression in ovarian cancer.

\begin{tabular}{|c|c|c|c|c|c|c|}
\hline & \multicolumn{3}{|c|}{ Overall survival } & \multicolumn{3}{|c|}{ Progression-free survival } \\
\hline & Cases & HR $(95 \%$ CI $)$ & $p$ value & Cases & HR $(95 \%$ CI $)$ & $p$ value \\
\hline \multicolumn{7}{|l|}{ Histology } \\
\hline All cancer patients & 1656 & $1.25(1.08-1.44)$ & $0.0031^{*}$ & 1435 & $0.89(0.77-1.03)$ & 0.13 \\
\hline Serous cancer patients & 1207 & $1.25(1.05-1.48)$ & $0.0099^{*}$ & 1104 & $0.88(0.75-1.05)$ & 0.15 \\
\hline Endometrioid cancer patients & 37 & $5.91(0.66-52.98)$ & 0.071 & 51 & $0.34(0.12-0.95)$ & $0.031^{*}$ \\
\hline \multicolumn{7}{|l|}{ Pathological grades } \\
\hline I & 56 & $0.59(0.23-1.53)$ & 0.28 & 37 & $2.67(0.89-7.96)$ & 0.068 \\
\hline II & 324 & $1.36(1.01-1.84)$ & $0.045^{*}$ & 256 & $0.81(0.58-1.13)$ & 0.22 \\
\hline III & 1015 & $0.88(0.74-1.03)$ & 0.12 & 837 & $0.83(0.68-1.01)$ & 0.062 \\
\hline \multicolumn{7}{|l|}{ Clinical stages } \\
\hline I and II & 135 & $1.56(0.72-3.4)$ & 0.26 & 163 & $0.59(0.31-1.14)$ & 0.12 \\
\hline III and IV & 1220 & $1.2(1.02-1.41)$ & $0.028^{*}$ & 1081 & $0.89(0.75-1.05)$ & 0.15 \\
\hline \multicolumn{7}{|l|}{ Chemotherapy } \\
\hline Contains platin & 1409 & $1.21(1.04-1.41)$ & $0.014^{*}$ & 1259 & $1.12(0.99-1.28)$ & 0.078 \\
\hline Contains taxol & 793 & $1.15(0.94-1.4)$ & 0.17 & 715 & $0.82(0.67-1)$ & $0.049^{*}$ \\
\hline Contains taxol+platin & 776 & $1.13(0.92-1.38)$ & 0.24 & 698 & $0.8(0.65-0.98)$ & $0.029^{*}$ \\
\hline
\end{tabular}

[32]. Moreover, the overexpression of IGFBP3 is correlated with better respond rate to first-line chemotherapy and extended time of tumor progression and OS among metastatic colorectal cancer patients without receiving treatment previously [33]. Numerous researches have pointed out that the IGFBP3 overexpression is also in relation with the favorable survival in lung cancer [34], hepatocellular carcinoma [35], breast cancer [36], bladder carcinoma [37], esophageal squamous cell cancer [38], and pancreatic ductal adenocarcinoma [39]. However, raised levels of IGFBP3 are correlated with reduced survival in glioblastoma multiforme [40]. Furthermore, IGFBP3 regulated by miR-19a-3p can inhibit the proliferation, migration, and invasion in OC cells [41]. Increased levels of IGFBP3 are closely associated with an early clinical stage, nonserous histology, optimal cytoreduction, and favorable OS and PFS in epithelial ovarian cancer [31]. In a study of EOC, IGFBP3 acted as an invasion-metastasis inhibitor through the IGF-independent pathway; besides, lower expression of IGFBP3 induced higher pathological grade, advanced clinical stage, and worse survival [42]. Consistently, our results also 
TABLE 4: The prognostic value of the IGFBP4 mRNA expression in ovarian cancer.

\begin{tabular}{|c|c|c|c|c|c|c|}
\hline & \multicolumn{3}{|c|}{ Overall survival } & \multicolumn{3}{|c|}{ Progression-free survival } \\
\hline & Cases & HR (95\% CI) & $p$ value & Cases & HR $(95 \% \mathrm{CI})$ & $p$ value \\
\hline \multicolumn{7}{|l|}{ Histology } \\
\hline All cancer patients & 1656 & $1.14(0.99-1.3)$ & 0.068 & 1435 & $0.94(0.83-1.06)$ & 0.32 \\
\hline Serous cancer patients & 1207 & $1.17(1-1.37)$ & $0.047^{*}$ & 1104 & $1.24(1.07-1.44)$ & $0.005^{*}$ \\
\hline Endometrioid cancer patients & 37 & $2.81(0.31-25.11)$ & 0.34 & 51 & $0.1(0.01-0.79)$ & $0.0077^{*}$ \\
\hline \multicolumn{7}{|l|}{ Pathological grades } \\
\hline I & 56 & $0.19(0.03-1.47)$ & 0.076 & 37 & $0.24(0.05-1.09)$ & $0.045^{*}$ \\
\hline II & 324 & $1.41(1.04-1.92)$ & $0.026^{*}$ & 256 & $1.52(1.11-2.09)$ & $0.0085^{*}$ \\
\hline III & 1015 & $1.18(0.98-1.42)$ & 0.08 & 837 & $1.23(1-1.5)$ & $0.045^{*}$ \\
\hline \multicolumn{7}{|l|}{ Clinical stages } \\
\hline I and II & 135 & $1.47(0.67-3.21)$ & 0.33 & 163 & $0.34(0.19-0.6)$ & $8.7 \mathrm{e}-05^{*}$ \\
\hline III and IV & 1220 & $1.16(0.99-1.35)$ & 0.065 & 1081 & $1.34(1.15-1.56)$ & $0.00015^{*}$ \\
\hline \multicolumn{7}{|l|}{ Chemotherapy } \\
\hline Contains platin & 1409 & $1.24(1.06-1.44)$ & $0.0067^{*}$ & 1259 & $1.1(0.96-1.27)$ & 0.17 \\
\hline Contains taxol & 793 & $1.15(0.95-1.4)$ & 0.15 & 715 & $1.21(1.02-1.45)$ & $0.029^{*}$ \\
\hline Contains taxol+platin & 776 & $1.18(0.97-1.43)$ & 0.1 & 698 & $1.23(1.03-1.47)$ & $0.022^{*}$ \\
\hline
\end{tabular}

TABLE 5: The prognostic value of the IGFBP5 mRNA expression in ovarian cancer.

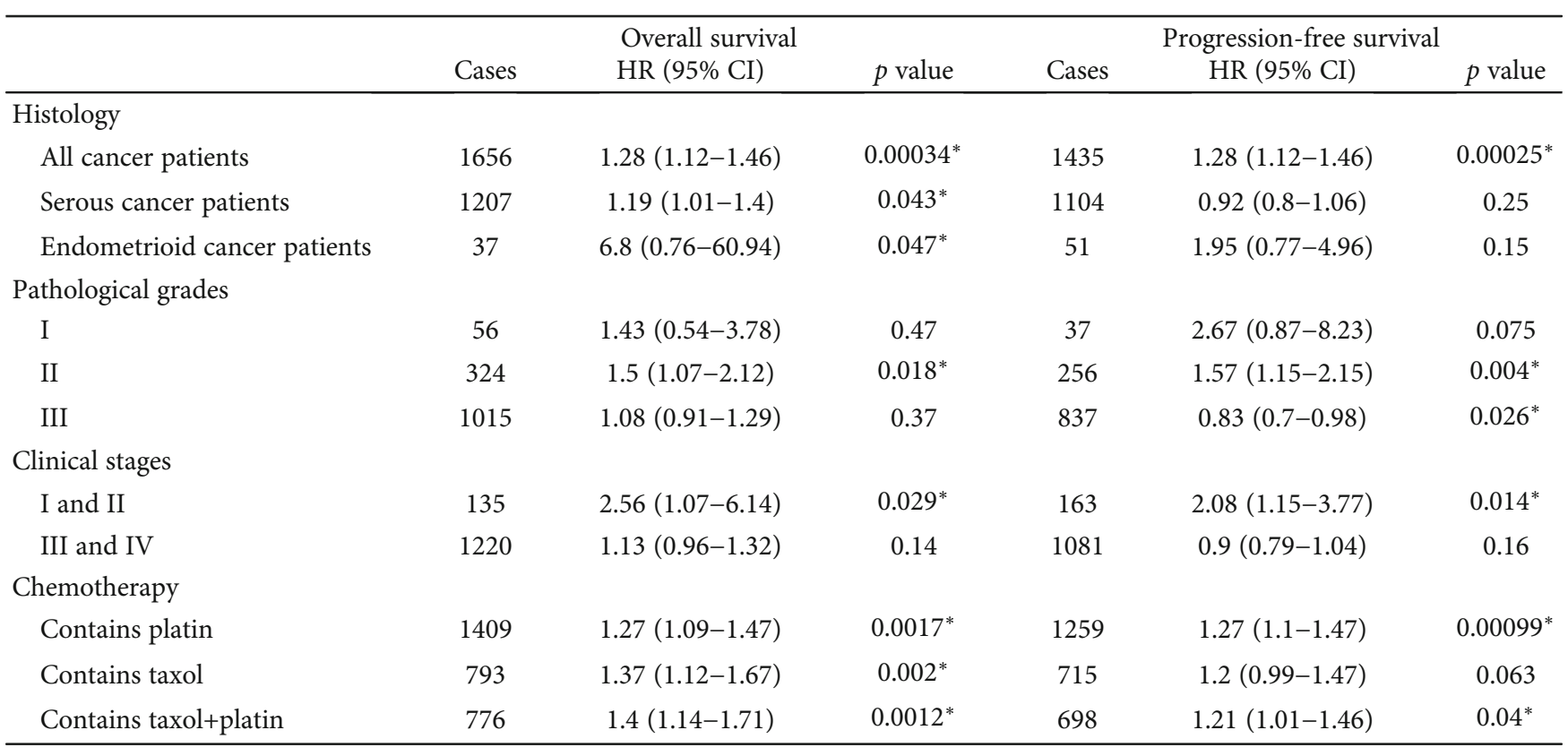

${ }^{*} p<0.05$.

showed that IGFBP3 predicted favorable PFS in EOC patients. Nevertheless, we observed that the overexpression of IGFBP3 mRNA was related to worsen OS in all OC and SOC patients. Therefore, these findings suggest that further research on the role of IGFBP3 in OC is required.

Elevated expression of IGFBP4 can lead to positive disease-free survival and OS in breast carcinoma [43], while IGFBP4 has a tumor-promoting effect on renal cell carci- noma by activating the $\mathrm{Wnt} / \beta$-catenin signaling pathway [44]. High expression of IGFBP4 is related to metastasis and worse median survival rate in lung cancer [45]. Additionally, Mosig et al. first observed that both of IGFBP4 serum and tumor levels were elevated among all stages of epithelial ovarian cancer patients [46]. Our results from the Oncomine database clarified that the IGFBP4 mRNA expression was significantly highly expressed in OC. Nevertheless, 
TABLE 6: The prognostic value of the IGFBP6 mRNA expression in ovarian cancer.

\begin{tabular}{|c|c|c|c|c|c|c|}
\hline & Cases & $\begin{array}{l}\text { Overall survival } \\
\text { HR ( } 95 \% \text { CI) }\end{array}$ & $p$ value & Cases & $\begin{array}{l}\text { Progression-free survival } \\
\text { HR }(95 \% \text { CI })\end{array}$ & $p$ value \\
\hline \multicolumn{7}{|l|}{ Histology } \\
\hline All cancer patients & 1656 & $1.19(1.05-1.35)$ & $0.0079^{*}$ & 1435 & $1.2(1.04-1.39)$ & $0.011^{*}$ \\
\hline Serous cancer patients & 1207 & $1.27(1.09-1.49)$ & $0.0023^{*}$ & 1104 & $1.29(1.12-1.49)$ & $0.00046^{*}$ \\
\hline Endometrioid cancer patients & 37 & $0.32(0.05-1.92)$ & 0.19 & 51 & $1.76(0.58-5.35)$ & 0.31 \\
\hline \multicolumn{7}{|l|}{ Pathological grades } \\
\hline I & 56 & $1.48(0.55-3.96)$ & 0.43 & 37 & $2.68(0.9-7.98)$ & 0.066 \\
\hline II & 324 & $1.29(0.95-1.74)$ & 0.097 & 256 & $1.7(1.22-2.39)$ & $0.0017^{*}$ \\
\hline III & 1015 & $1.27(1.06-1.53)$ & $0.0084^{*}$ & 837 & $1.31(1.11-1.54)$ & $0.0015^{*}$ \\
\hline \multicolumn{7}{|l|}{ Clinical stages } \\
\hline I and II & 135 & $0.53(0.24-1.18)$ & 0.11 & 163 & $1.42(0.8-2.53)$ & 0.23 \\
\hline III and IV & 1220 & $1.14(0.98-1.33)$ & 0.082 & 1081 & $1.26(1.09-1.45)$ & $0.0015^{*}$ \\
\hline \multicolumn{7}{|l|}{ Chemotherapy } \\
\hline Contains platin & 1409 & $1.21(1.05-1.39)$ & $0.0069^{*}$ & 1259 & $1.12(0.96-1.3)$ & 0.15 \\
\hline Contains taxol & 793 & $1.17(0.97-1.41)$ & 0.1 & 715 & $1.27(1.05-1.53)$ & $0.012^{*}$ \\
\hline Contains taxol+platin & 776 & $1.13(0.93-1.37)$ & 0.21 & 698 & $1.26(1.05-1.53)$ & $0.015^{*}$ \\
\hline
\end{tabular}

${ }^{*} p<0.05$.

there is paucity of study regarding prognosis effects of IGFBP4 in OC. In this study, the overexpression of IGFBP4 was in relation to worsen OS and PFS in SOC patients. High IGFBP4 was linked to a worsen OS in all OC patients received with platin chemotherapy. Overall, these findings collectively suggested that IGFBP4 might predict a poor outcome in women with SOC.

IGFBP5 plays as a tumor suppressor in breast cancer through estradiol-triggered activation of the Akt/PKB pathway [47]. Lower serum levels of IGFBP5 are correlated with a positive lymph node status and poor recurrence-free survival in lung cancer [48]. However, the overexpression of IGFBP5 is related to poor prognosis in ER-negative breast cancer patients with positive lymph nodes [49]. Furthermore, elevated levels of IGFBP5 are correlated to advanced stages, worse disease-specific survival, and metastatic-free survival in urothelial cancers of upper urinary tracts and urinary bladder [50]. C-terminus of IGFBP5 exhibited antitumor effect by suppressing angiogenesis through the Akt/ERK and NF- $\kappa$ B-VEGF/MMP-9 pathway in OC [51]. On the contrary, Wang et al. have detected increased IGFBP5 protein levels in high-grade SOCs in comparison with healthy surface epithelium, serous benign cysts, borderline serous neoplasms, and low-grade SOCs [52]. Discordant with this research, our data from the GEPIA database pointed out that IGFBP5 mRNA levels were remarkably reduced in SOC than in healthy specimens. Additionally, this present study is the first one to report on the prognosis of IGFBP5, which exhibited that high IGFBP5 was linked to poor OS and PFS in all OC patients and all OC patients that received with platin and taxol+platin treatments. IGFBP5 also predicted a worsen OS in all OC patients that received with taxol chemotherapeutic regimen. As pointed out above, IGFBP5 may predict a reduced prognosis in OC, especially in SOC patients. The overexpression of IGFBP5 may result in chemotherapy resistance in patients receiving platin and taxol+platin regimens.

IGFBP6 encourages migration in rhabdomyosarcoma cells via mediating the MAP kinase signaling pathway [53], while IGFBP6 plays a suppressive role on tumor growth in ACTH-secreting pituitary adenoma through activation of the PI3K-AKT-mTOR signaling pathway [54]. In addition, IGFBP6 is inversely associated with glioma grade and predicts better survival [55]. The low expression of IGFBP6 is related to poor clinical outcomes and unfavorable prognosis in gastric adenocarcinoma [56]. Moreover, IGFBP6 promotes migration in SKOV3 OC cells via activation of the MAP kinase signaling pathway, whereas IGFBP6 represses migration in HEY OC cells through both the IGF-dependent and IGF-independent pathway [57]. Gunawardana et al. noticed that the IGFBP6 expression in serum was significantly decreased in epithelial ovarian cancer compared to the healthy ovarian tissue [58]. Using information from HPA datasets, we observed that IGFBP6 protein levels were upregulated in both of SOC and EOC tissues when compared to normal tissues. However, there are limited studies on the prognosis of IGFBP6 in women with OC. Our data from the KM plotter database demonstrated that the overexpression of IGFBP6 was linked to worsen OS and PFS in all OC patients, SOC patients, and pathological grade III patients. Meanwhile, IGFBP6 predicted a worse OS in all OC patients received with platin treatment and worse PFS in pathological grade II patients, clinical stage III and IV patients, and all women received taxol and taxol+platin chemotherapeutic regimens. Accumulated evidence indicated that IGFBP6 may be a poor outcome predictor in OC, especially among poor differentiated and SOC patients. 


\section{Conclusions}

Taken together, this study indicates that IGFBP2 and IGFBP4 are potential biomarkers for the diagnosis of OC. High IGFBP1 mRNA is in relation to positive OS and PFS in all OC patients. By contrast, high IGFBP5 and IGFBP6 mRNA levels are linked to worsen OS and PFS in all OC patients. Moreover, high IGFBP4 and IGFBP6 mRNA predict worsen OS and PFS in women with SOC. Different IGFBPs are associated with various pathological grades and clinical stages, and IGFBP1/2/4/5/6 are useful prognostic indicators for chemotherapeutic effect in patients with OC.

\section{Data Availability}

The data used in this article to support the findings are included in the documentation.

\section{Conflicts of Interest}

All the authors declare that they have no competing interests.

\section{Acknowledgments}

This work was supported by the Science and Technology Bureau of Wenzhou [No. Y20180278, No. Y2020937].

\section{References}

[1] Global Burden of Disease Cancer Collaboration, C. Fitzmaurice, D. Abate et al., "Global, Regional, and National Cancer Incidence, Mortality, Years of Life Lost, Years Lived With Disability, and Disability-Adjusted Life-Years for 29 Cancer Groups, 1990 to 2017," JAMA Oncology, vol. 5, no. 12, pp. 1749-1768, 2019.

[2] M.-A. Lisio, L. Fu, A. Goyeneche, Z.-h. Gao, and C. Telleria, "High-Grade Serous Ovarian Cancer: Basic Sciences, Clinical and Therapeutic Standpoints," International journal of Molecular Sciences, vol. 20, no. 4, p. 952, 2019.

[3] L. A. Torre, F. Islami, R. L. Siegel, E. M. Ward, and A. Jemal, "Global cancer in women: burden and trends," Cancer Epidemiology, Biomarkers \& Prevention, vol. 26, no. 4, pp. 444457, 2017.

[4] R. C. Baxter, "IGF binding proteins in cancer: mechanistic and clinical insights," Nature Reviews Cancer, vol. 14, no. 5, pp. 329-341, 2014.

[5] S. M. Firth and R. C. Baxter, "Cellular actions of the insulinlike growth factor binding proteins," Endocrine Reviews, vol. 23, no. 6, pp. 824-854, 2002.

[6] D. R. Rhodes, J. Yu, K. Shanker et al., "ONCOMINE: a cancer microarray database and integrated data-mining platform," Neoplasia, vol. 6, no. 1, pp. 1-6, 2004.

[7] Z. Tang, C. Li, B. Kang, G. Gao, C. Li, and Z. Zhang, "GEPIA: a web server for cancer and normal gene expression profiling and interactive analyses," Nucleic Acids Research, vol. 45, no. W1, pp. W98-w102, 2017.

[8] C. Lindskog, "The human protein atlas - an important resource for basic and clinical research," Expert Review of Proteomics, vol. 13, no. 7, pp. 627-629, 2016.

[9] B. Györffy, A. Lanczky, A. C. Eklund et al., "An online survival analysis tool to rapidly assess the effect of 22, 277 genes on breast cancer prognosis using microarray data of 1,809 patients," Breast Cancer Research and Treatment, vol. 123, no. 3, pp. 725-731, 2010.

[10] T. Bonome, D. A. Levine, J. Shih et al., "A gene signature predicting for survival in suboptimally debulked patients with ovarian cancer," Cancer Research, vol. 68, no. 13, pp. 54785486, 2008.

[11] M.-C. Beauchamp, A. Yasmeen, A. Knafo, and W. H. Gotlieb, "Targeting insulin and insulin-like growth factor pathways in epithelial ovarian cancer," Journal of Oncology, vol. 2010, Article ID 257058, 257011 pages, 2010.

[12] S. Ammoun, M. C. Schmid, L. Zhou et al., "Insulin-like growth factor-binding protein-1 (IGFBP-1) regulates human schwannoma proliferation, adhesion and survival," Oncogene, vol. 31, no. 13, pp. 1710-1722, 2012.

[13] B. Dai, B. Ruan, J. Wu et al., "Insulin-like growth factor binding protein-1 inhibits cancer cell invasion and is associated with poor prognosis in hepatocellular carcinoma," International Journal of Clinical and Experimental Pathology, vol. 7, no. 9, pp. 5645-5654, 2014.

[14] Y. Sato, M. Inokuchi, Y. Takagi, and K. Kojima, "IGFBP1 is a predictive factor for Haematogenous metastasis in patients with gastric Cancer," Anticancer Research, vol. 39, no. 6, pp. 2829-2837, 2019.

[15] J. Sharma, K. P. Gray, C. Evan et al., "Elevated insulin-like growth factor binding protein-1 (IGFBP-1) in men with metastatic prostate cancer starting androgen deprivation therapy (ADT) is associated with shorter time to castration resistance and overall survival," The Prostate, vol. 74, no. 3, pp. 225234, 2014

[16] P. J. Goodwin, M. Ennis, K. I. Pritchard et al., "Insulin-like growth factor binding proteins 1 and 3 and breast cancer outcomes," Breast Cancer Research and Treatment, vol. 74, no. 1, pp. 65-76, 2002.

[17] B. M. Wolpin, J. A. Meyerhardt, A. T. Chan et al., "Insulin, the insulin-like growth factor axis, and mortality in patients with nonmetastatic colorectal cancer," Journal of Clinical Oncology, vol. 27, no. 2, pp. 176-185, 2009.

[18] S. Sugita, Y. Morishita, J. Kano, S. Furuya, A. Shiba-Ishii, and M. Noguchi, "IGFBP-1 is expressed specifically in ovarian clear cell adenocarcinoma," Histopathology, vol. 58, no. 5, pp. 729-738, 2011.

[19] L. D. Maso, L. S. A. Augustin, S. Franceschi et al., "Association between components of the insulin-like growth factor system and epithelial ovarian cancer risk," Oncology, vol. 67, no. 3-4, pp. 225-230, 2004.

[20] D. R. Clemmons, "Insulin-like growth factor binding proteins and their role in controlling IGF actions," Cytokine \& Growth Factor Reviews, vol. 8, no. 1, pp. 45-62, 1997.

[21] S. S. Patil, P. Gokulnath, M. Bashir et al., "Insulin-like growth factor binding protein- 2 regulates $\beta$-catenin signaling pathway in glioma cells and contributes to poor patient prognosis," Neuro Oncology, vol. 18, no. 11, pp. 1487-1497, 2016.

[22] C. Y. Chua, Y. Liu, K. J. Granberg et al., "IGFBP2 potentiates nuclear EGFR-STAT3 signaling," Oncogene, vol. 35, no. 6, pp. 738-747, 2016.

[23] S. Gao, Y. Sun, X. Zhang et al., "IGFBP2 activates the NF- $\kappa$ B pathway to drive epithelial-mesenchymal transition and invasive character in pancreatic ductal adenocarcinoma," Cancer Research, vol. 76, no. 22, pp. 6543-6554, 2016. 
[24] M. G. Moore, L. A. Wetterau, M. J. Francis, D. M. Peehl, and P. Cohen, "Novel stimulatory role for insulin-like growth factor binding protein-2 in prostate cancer cells," International Journal of Cancer, vol. 105, no. 1, pp. 14-19, 2003.

[25] Z. Kang, Y. Yu, Y. J. Zhu et al., "Downregulation of IGFBP2 is associated with resistance to IGF1R therapy in rhabdomyosarcoma," Oncogene, vol. 33, no. 50, pp. 5697-5705, 2014.

[26] A. I. So, R. J. Levitt, B. Eigl et al., "Insulin-like growth factor binding protein-2 is a novel therapeutic target associated with breast cancer," Clinical Cancer Research, vol. 14, no. 21, pp. 6944-6954, 2008.

[27] A. Chao, C. Y. Lin, R. C. Wu et al., "The combination of everolimus and terameprocol exerts synergistic antiproliferative effects in endometrial cancer: molecular role of insulin-like growth factor binding protein 2," Journal of Molecular Medicine, vol. 96, no. 11, pp. 1251-1266, 2018.

[28] J. M. Liou, C. T. Shun, J. T. Liang et al., "Plasma insulin-like growth factor-binding protein-2 levels as diagnostic and prognostic biomarker of colorectal cancer," The Journal of Clinical Endocrinology and Metabolism, vol. 95, no. 4, pp. 1717-1725, 2010.

[29] Q. Hu, L. Huang, X. Kuang et al., "Is insulin-like growth factor binding protein 2 associated with metastasis in lung cancer?," Clinical \& Experimental Metastasis, vol. 31, no. 5, pp. 535541, 2014.

[30] S. Baron-Hay, F. Boyle, A. Ferrier, and C. Scott, "Elevated Serum Insulin-Like Growth Factor Binding Protein-2 as a Prognostic Marker in Patients with Ovarian Cancer," Clinical Cancer Research, vol. 10, no. 5, pp. 1796-1806, 2004.

[31] Y. F. Huang, W. F. Cheng, Y. P. Wu, Y. M. Cheng, K. F. Hsu, and C. Y. Chou, "Circulating IGF system and treatment outcome in epithelial ovarian cancer," Endocrine-Related Cancer, vol. 21, no. 2, pp. 217-229, 2014.

[32] J. Han, S. Jogie-Brahim, A. Harada, and Y. Oh, "Insulin-like growth factor-binding protein-3 suppresses tumor growth via activation of caspase-dependent apoptosis and cross-talk with NF- $\kappa$ B signaling," Cancer Letters, vol. 307, no. 2, pp. 200-210, 2011.

[33] C. S. Fuchs, R. M. Goldberg, D. J. Sargent et al., "Plasma insulin-like growth factors, insulin-like binding protein-3, and outcome in metastatic colorectal cancer: results from intergroup trial N9741," Clinical Cancer Research, vol. 14, no. 24, pp. 8263-8269, 2008.

[34] S. H. Oh, O. H. Lee, C. P. Schroeder et al., "Antimetastatic activity of insulin-like growth factor binding protein-3 in lung cancer is mediated by insulin-like growth factor-independent urokinase-type plasminogen activator inhibition," Molecular Cancer Therapeutics, vol. 5, no. 11, pp. 2685-2695, 2006.

[35] S. Aishima, Y. Basaki, Y. Oda et al., "High expression of insulin-like growth factor binding protein-3 is correlated with lower portal invasion and better prognosis in human hepatocellular carcinoma," Cancer Science, vol. 97, no. 11, pp. 1182-1190, 2006.

[36] L. Mu, D. Katsaros, A. Wiley et al., "Peptide concentrations and mRNA expression of IGF-I, IGF-II and IGFBP-3 in breast cancer and their associations with disease characteristics," Breast Cancer Research amd Treatment, vol. 115, no. 1, pp. 151-162, 2009.

[37] S. F. Shariat, J. Kim, C. Nguyen, T. M. Wheeler, S. P. Lerner, and K. M. Slawin, "Correlation of preoperative levels of IGFI and IGFBP-3 with pathologic parameters and clinical out- come in patients with bladder cancer," Urology, vol. 61, no. 2, pp. 359-364, 2003.

[38] L. Zhao, L. R. He, R. Zhang et al., "Low expression of IGFBP-3 predicts poor prognosis in patients with esophageal squamous cell carcinoma," Medical Oncology, vol. 29, no. 4, pp. 26692676, 2012.

[39] A. Gheysarzadeh, H. Bakhtiari, A. Ansari, A. Emami Razavi, M. H. Emami, and M. R. Mofid, "The insulin-like growth factor binding protein-3 and its death receptor in pancreatic ductal adenocarcinoma poor prognosis," Journal of Cellular Physiology, vol. 234, no. 12, pp. 23537-23546, 2019.

[40] H. Abdolhoseinpour, F. Mehrabi, K. Shahraki et al., "Investigation of serum levels and tissue expression of two genes IGFBP2 and IGFBP-3 act as potential biomarker for predicting the progression and survival in patients with glioblastoma multiforme," Journal of the Neurological Sciences, vol. 366, pp. 202-206, 2016.

[41] R. Bai, Z. Cui, Y. Ma et al., "The NF- $\kappa$ B-modulated miR-19a$3 p$ enhances malignancy of human ovarian cancer cells through inhibition of IGFBP-3 expression," Molecular Carcinogenesis, vol. 58, no. 12, pp. 2254-2265, 2019.

[42] P. L. Torng, Y. C. Lee, C. Y. Huang et al., "Insulin-like growth factor binding protein-3 (IGFBP-3) acts as an invasionmetastasis suppressor in ovarian endometrioid carcinoma," Oncogene, vol. 27, no. 15, pp. 2137-2147, 2008.

[43] K. Mita, Z. Zhang, Y. Ando et al., "Prognostic significance of insulin-like growth factor binding protein (IGFBP)-4 and IGFBP-5 expression in breast cancer," Japanese Journal of Clinical Oncology, vol. 37, no. 8, pp. 575-582, 2007.

[44] K. Ueno, H. Hirata, S. Majid, Z. L. Tabatabai, Y. Hinoda, and R. Dahiya, "IGFBP-4 activates the Wnt/beta-catenin signaling pathway and induces M-CAM expression in human renal cell carcinoma," International Journal of Cancer, vol. 129, no. 10, pp. 2360-2369, 2011.

[45] Y. Xiao, S. Zhu, W. Yin, X. Liu, and Y. Hu, "IGFBP-4 expression is adversely associated with lung cancer prognosis," Oncology Letters, vol. 14, no. 6, pp. 6876-6880, 2017.

[46] R. A. Mosig, M. Lobl, E. Senturk et al., "IGFBP-4 tumor and serum levels are increased across all stages of epithelial ovarian cancer," Journal of Ovarian Research, vol. 5, no. 1, p. 3, 2012.

[47] A. Hermani, A. Shukla, S. Medunjanin, H. Werner, and D. Mayer, "Insulin-like growth factor binding protein-4 and -5 modulate ligand-dependent estrogen receptor- $\alpha$ activation in breast cancer cells in an IGF-independent manner," Cellular Signalling, vol. 25, no. 6, pp. 1395-1402, 2013.

[48] D. D. Shersher, M. S. Vercillo, C. Fhied et al., "Biomarkers of the insulin-like growth factor pathway predict progression and outcome in lung cancer," The Annals of Thoracic Surgery, vol. 92, no. 5, pp. 1805-1811, 2011.

[49] X. Li, X. Cao, X. Li, W. Zhang, and Y. Feng, "Expression level of insulin-like growth factor binding protein $5 \mathrm{mRNA}$ is a prognostic factor for breast cancer," Cancer Science, vol. 98, no. 10, pp. 1592-1596, 2007.

[50] P. I. Liang, Y. H. Wang, T. F. Wu et al., "IGFBP-5 overexpression as a poor prognostic factor in patients with urothelial carcinomas of upper urinary tracts and urinary bladder," Journal of Clinical Pathology, vol. 66, no. 7, pp. 573-582, 2013.

[51] J. R. Hwang, Y. J. Cho, Y. Lee et al., "The C-terminus of IGFBP-5 suppresses tumor growth by inhibiting angiogenesis," Scientific Reports, vol. 6, no. 1, 2016. 
[52] H. Wang, D. G. Rosen, H. Wang, G. N. Fuller, W. Zhang, and J. Liu, "Insulin-like growth factor-binding protein 2 and 5 are differentially regulated in ovarian cancer of different histologic types," Modern Pathology, vol. 19, no. 9, pp. 1149-1156, 2006.

[53] P. Fu, G. J. Liang, S. S. Khot, R. Phan, and L. A. Bach, "Crosstalk between MAP kinase pathways is involved in IGF-independent, IGFBP-6-induced Rh30 rhabdomyosarcoma cell migration," Journal of Cellular Physiology, vol. 224, no. 3, pp. 636-643, 2010.

[54] Y. Yang, M. Sheng, F. Huang et al., "Downregulation of insulin-like growth factor binding protein 6 is associated with ACTH-secreting pituitary adenoma growth," Pituitary, vol. 17, no. 6, pp. 505-513, 2014.

[55] Y. Bei, Q. Huang, J. Shen et al., "IGFBP6 Regulates Cell Apoptosis and Migration in Glioma," Cell Molecular Neurobiology, vol. 37, no. 5, pp. 889-898, 2017.

[56] C. Zeng, X. Feng, W. Wang et al., "Decreased expression of insulin-like growth factor binding protein 6 is associated with gastric adenocarcinoma prognosis," Oncology Letters, vol. 13, no. 6, pp. 4161-4168, 2017.

[57] Z. Yang and L. A. Bach, "Differential Effects of Insulin-Like Growth Factor Binding Protein-6 (IGFBP-6) on Migration of Two Ovarian Cancer Cell Lines," Frontiers in Endocrinology, vol. 5, 2015.

[58] C. G. Gunawardana, C. Kuk, C. R. Smith, I. Batruch, A. Soosaipillai, and E. P. Diamandis, "Comprehensive analysis of conditioned media from ovarian cancer cell lines identifies novel candidate markers of epithelial ovarian cancer," Journal of Proteome Research, vol. 8, no. 10, pp. 4705-4713, 2009. 